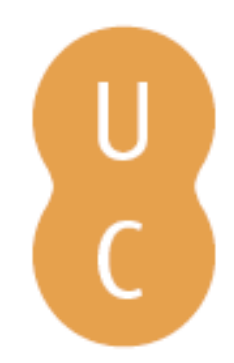

\title{
nombalina
}

\section{Litologias gnaisso-migmatíticas da faixa costeira Lavadores-Madalena: possível significado das paragéneses com hercinite}
Autor(es):
Ribeiro, Maria dos Anjos; Sant'Ovaia, Helena; Dória, Armanda
Publicado por:
Imprensa da Universidade de Coimbra; Laboratório de Radioactividade
URL persistente: Natural da Universidade de Coimbra
DOI:
URI:http://hdl.handle.net/10316.2/36314
DOl:http://dx.doi.org/10.14195/978-989-26-1009-2_25
Accessed : $\quad$ 26-Apr-2023 09:52:19

A navegação consulta e descarregamento dos títulos inseridos nas Bibliotecas Digitais UC Digitalis, UC Pombalina e UC Impactum, pressupõem a aceitação plena e sem reservas dos Termos e Condições de Uso destas Bibliotecas Digitais, disponíveis em https://digitalis.uc.pt/pt-pt/termos.

Conforme exposto nos referidos Termos e Condições de Uso, o descarregamento de títulos de acesso restrito requer uma licença válida de autorização devendo o utilizador aceder ao(s) documento(s) a partir de um endereço de IP da instituição detentora da supramencionada licença.

Ao utilizador é apenas permitido o descarregamento para uso pessoal, pelo que o emprego do(s) título(s) descarregado(s) para outro fim, designadamente comercial, carece de autorização do respetivo autor ou editor da obra.

Na medida em que todas as obras da UC Digitalis se encontram protegidas pelo Código do Direito de Autor e Direitos Conexos e demais legislação aplicável, toda a cópia, parcial ou total, deste documento, nos casos em que é legalmente admitida, deverá conter ou fazer-se acompanhar por este aviso.

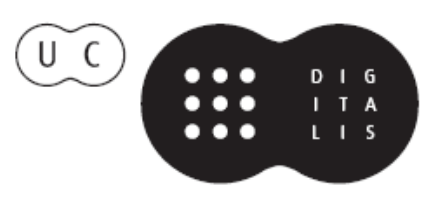




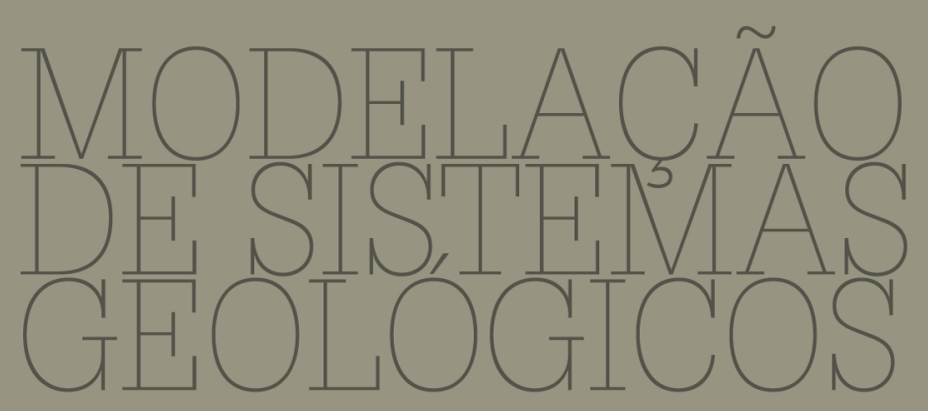

Homenagem ao Professor Doutor Manuel Maria Godinho

L.J.P.F. Neves, A.J.S.C. Pereira,

C.S.R. Gomes, L.C.G. Pereira,

A.O. TAVARES

IMPRENSA DA UNIVERSIDADE DE COIMBRA

CoImBra University Press 


\title{
MODELAÇÃO \\ DE SISTEMAS \\ GEOLÓGICOS
}

Homenagem ao Professor Manuel Maria Godinho

\section{Litologias gnaisso-migmatíticas da faixa costeira Lavadores-Madalena: possível significado das paragéneses com hercinite}

\author{
Maria dos Anjos Ribeiro'; Helena Sant'Ovaia'; Armanda Dória ${ }^{1}$ \\ ${ }^{1}$ DGAOT-FCUP/Centro de Geologia da UP, PORTUGAL, maribeir@fc.up.pt
}

Palavras-chave: Diatexitos, Metatexitos, Hercinite

\section{Resumo}

$\mathrm{Na}$ zona costeira de Lavadores - Madalena afloram rochas migmatíticas de natureza diatexítica e metatexítica, no bordo ocidental do maciço granítico pós-tectónico de Lavadores. O bandado migmatítico apresenta uma orientação geral NNW-SSE a NW-SE com dobramentos interfoliais fortemente assimétricos, de eixo em geral subvertical, mergulhante para SE. As litologias diatexíticas são leucocratas a mesocratas, sem foliação ou com foliação incipiente, de orientação muito irregular. As litologias metatexitícas apresentam foliação bem marcada no paleossoma metapelítico ou quarzto-pelítico, de orientação $\mathrm{N} 120^{\circ}-\mathrm{N} 140^{\circ}, 75^{\circ} \mathrm{SW}$. O neossoma ocorre em lentículas irregulares, alongadas paralelamente à foliação do paleossoma, e apresenta tendência porfiróide. Nos diatexitos, quer na paragénese do paleossoma quer na paragénese do neossoma, existe hercinite com composição rica em $\mathrm{Zn}$ em $\mathrm{Mg}$, em associação com silimanite e magnetite.

Key-words: Diatexites, Metatexites, Hercynite

\begin{abstract}
In Lavadores - Madalena coastal area outcrops, as host rocks at the western edge of the Lavadores post-tectonic granitic massif, migmatites (metatexites and diatexites). The banded migmatitic structure presents a general NNW-SSE to NW-SE orientation, and strong asymmetric interlayer folds with, generally subvertical axe, plunging to SE. The diatexites lithologies are leucocratic to mesocratic without foliation or with incipient one, with a very irregular orientation. The metatexites lithologies present a well defined foliation in the metapelitic or quarzt-pelitic paleosome, trending N120-N140 ${ }^{\circ}, 75^{\circ} \mathrm{SW}$. The neosome occurs as irregular lenticules, elongated parallel to the foliation paleosome, and with porphyritic tendency. In the diatexites paragenesis, either in the paleosome or in the neosome, occurs hercynite with a rich $\mathrm{Mg}$-Zn composition, in association with magnetite and silimanite.
\end{abstract}




\section{Introdução}

Na zona costeira a sul da foz do Rio Douro, no litoral da cidade de Vila Nova de Gaia, aflora uma faixa de rochas metamórficas, com grande heterogeneidade litológica, incluindo rochas gnaisso-migmatíticas, metassedimentos pelíticos (micaxistos e quartzo-micaxistos) e anfibolitos (Sant'Ovaia et al., 2008; Ribeiro et al., 2010). Estas litologias foram descritas em termos geológicos, estruturais, petrográficos, petrofísicos e mineralógicos em Sant'Ovaia et al. (2008, 2010) e em Ribeiro et al. (2010). Os estudos petrográficos e mineralógicos já efectuados evidenciaram a ocorrência de hercinite, com considerável conteúdo em $\mathrm{Zn}$, quer nas rochas metapelíticas, quer nas rochas gnaisso-migmatíticas associadas (Ribeiro et al., 2010). Estes trabalhos incidiram sobre os afloramentos metamórficos da Praia das Pedras Amarelas e da Praia de Lavadores, um pouco a norte.

Estão em desenvolvimento estudos petrográficos e mineralógicos dos afloramentos metamórficos das Praias de Madalena Norte e de Madalena Sul, cuja descrição litológica e estrutural agora se apresenta.

No seu conjunto, este maciço metamórfico, aflorante numa faixa costeira estreita e irregular, no contacto ocidental do maciço granítico de Lavadores, apresenta variações consideráveis por predominância de diferentes litologias: na Praia das Pedras Amarelas é notória uma predominância de fácies diatexíticas, com predominância de rochas leucocratas, ainda que tendo associadas de modo subordinado fácies mesocratas de granularidade fina essencialmente biotíticas (Ribeiro et al., 2010); nas Praias de Madalena Norte e de Madalena Sul são predominantes as fácies metatexíticas. O maciço não aflora de modo contínuo, quer devido à geometria do contacto intrusivo do Granito de Lavadores, quer porque fica tapado por depósitos arenosos do Quaternário, já um pouco consolidados, e pelos depósitos de praia actual. Embora as manchas de afloramento deste maciço metamórfico tenham exposição condicionada pela dinâmica costeira e pelas marés, quando expostas na zona de intermarés afloram sem alteração considerável.

\section{Contexto geológico}

Do ponto de vista geotectónico, este sector costeiro corresponde ao limite entre a Zona Centro Ibérica (ZCI) e a Zona Ossa Morena (ZOM), materializado numa zona de cisalhamento conhecida pela designação de Zona Cisalhamento Porto Tomar (ZCPT) (Ribeiro et al., 1980). O Granito de Lavadores, de carácter pós-tectónico, com uma idade de instalação de $298 \pm 12,3 \mathrm{Ma}$ (Martins et al., 2001), é intrusivo no maciço metamórfico 
atrás referido, tendo instalação pós-cinemática, controlada pelas estruturas transtensivas associadas à deformação cisalhante (Sant'Ovaia et al., 2008). De acordo com a bibliografia cartográfica, o Granito de Lavadores é intrusivo na Unidade de Lourosa, no bordo oriental (Oliveira et al., 2010) e no bordo ocidental (Chaminé, 2000). Porém segundo a Folha 1 da Carta Geológica de Portugal, à escala 1/200.000, no seu bordo oriental, o Maciço Granítico de Lavadores contacta com uma unidade de micaxistos, gnaisses e migmatitos atribuídos ao "Complexo Xisto-Grauváquico" -Grupo de Douro, indiferenciado.

O maciço metamórfico aflorante na zona costeira de Vila Nova de Gaia entre as Praias de Lavadores e de Madalena Sul, constituindo o encaixante no bordo ocidental do Granito de Lavadores, apresenta litologias diversas de carácter gnaisso-migmatítico, com litologias metatexíticas e diatexíticas, com deformação varisca, materializada numa geometria de carácter cisalhante direito, mais evidente nos sectores onde predominam rochas gnaisso-migmatíticas de carácter metatexítico, com estrutura estromática mais marcada (Ribeiro et al., 2010). O bandado migmatítico apresenta uma orientação geral NNW-SSE a NW-SE com dobramentos interfoliais fortemente assimétricos, de eixo em geral subvertical, mergulhante para SE. Os estudos do fabric magnético efectuado nestas litologias indicaram, igualmente, uma foliação magnética orientada NW-SE.

\section{Litologias diatexíticas}

As litologias diatexíticas afloram sobretudo na zona da Praia das Pedras Amarelas e na Praia de Salgueiros. Estas rochas apresentam características consonantes com as descritas por Sawyer (2008). Predominam rochas leucocratas sem foliação ou com foliação mais ou menos incipiente, com um padrão de orientação muito irregular. É a cor amarelada desta litologia predominante que é responsável pela designação da Praia. Afloram também, ainda que de modo subordinado, e com carácter intrusivos nas fácies leucocratas (Figura 1a), diatexitos mesocratas de granularidade fina, com abundantes lentículas restíticas, orientados paralelamente à foliação (Figura 1b). 


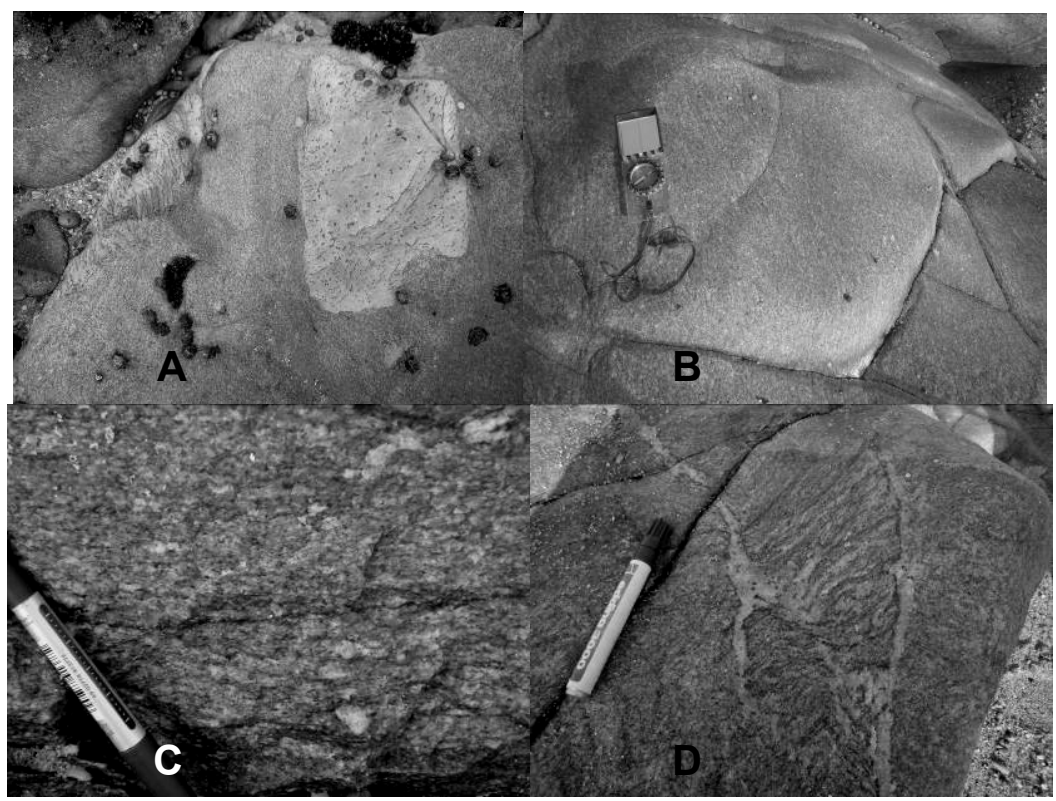

Figura 1. Aspectos litológicos dos diatexitos (200metros a sul dos rochedos das Pedras Amarelas, frente ao parque infantil).

As rochas diatexíticas mesocratas, quando os restitos são mais esporádicos, têm carácter isotrópico, e localmente apresentam tendência porfiróide (Figura 1c). Apresentam frequentes estruturas em rede ("diktyonitic structure"), marcadas por pequenos veios leucocratas, concordantes e secantes com a foliação (Figura 1d).

No afloramento do maciço metamórfico a norte das Pedras Amarelas (um pouco a sul do restaurante Casa Branca) as fácies leucocratas são minoritárias, predominando as rochas diatexíticas mesocratas finas com abundantes restitos, tendência porfiróide, e frequentes lentículas e vénulas pegmatíticas. $\mathrm{O}$ afloramento deste maciço destaca-se do ponto de vista morfológico, relativamente ao granito de Lavadores, por não ocorrerem os grandes blocos arredondados (Figura 2a).

A foliação nos diatexitos mesocratas é de carácter irregular, quer em termos de penetratividade quer em termos de orientação: $\mathrm{N}_{120^{\circ}}$ a $\mathrm{N} 170^{\circ}$. Apresentam fracturas com orientação $\mathrm{N} 35^{\circ}$ a $\mathrm{N} 60^{\circ}$, inclinando $25^{\circ}$ a $55^{\circ} \mathrm{N}$, com preenchimento cataclástico turmalinizado e com grande extensão lateral, embora com espessuras milimétricas (Figura 2b). 


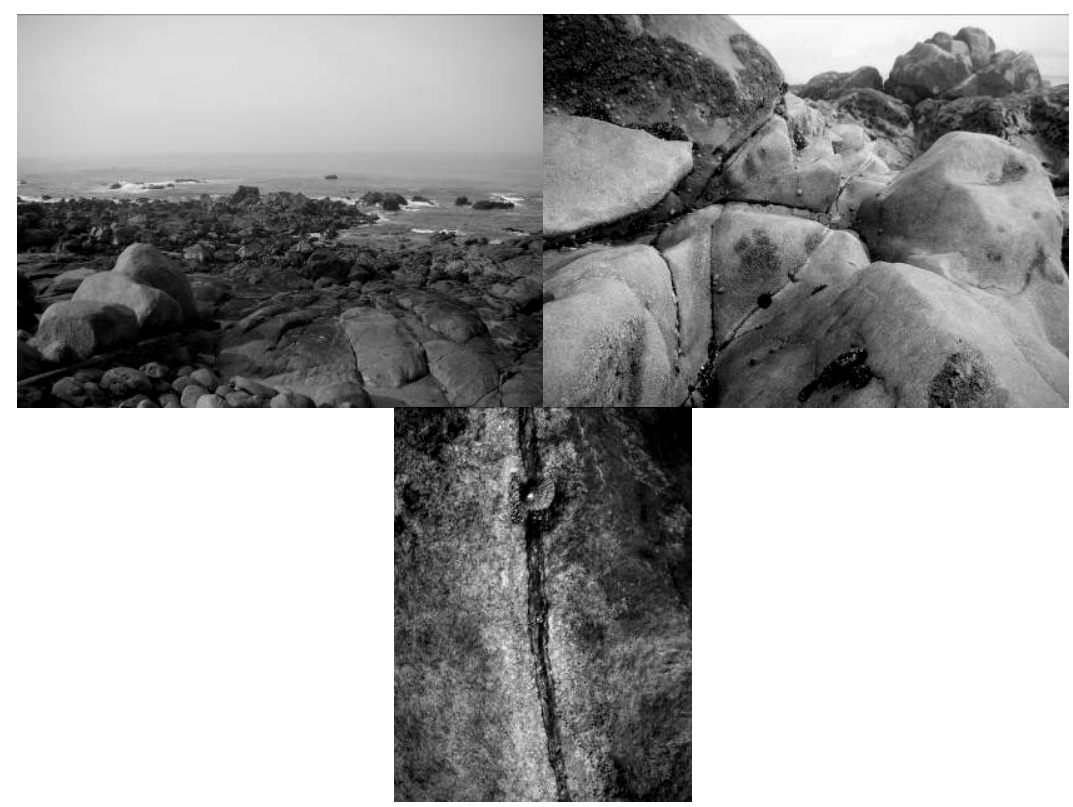

Figura 2. Aspectos morfológico e fracturação com preenchimento cataclástico turmalinizado das rochas diatexíticas mesocratas (frente ao Restaurante Casa Branca) .

\section{Litologias metatexíticas}

Nas Praias de Madalena Norte e de Madalena Sul afloram litologias migmatíticas, com larga predominância de metaxistos (Figura 3). Estas rochas apresentam foliação bem marcada no paleossoma metapelítico a quartzo-pelítico, com orientação $\mathrm{N} 120^{\circ}-\mathrm{N} 140^{\circ}, 75^{\circ} \mathrm{SW}$ (Figuras 3a e b). O neossoma ocorre em lentículas irregulares, alongadas paralelamente à foliação do paleossoma, e apresenta megacristais de feldspato subédricos a arredondados, mais ou menos dispersos, com dimensão que atinge $1 \mathrm{a} 2 \mathrm{~cm}$. Por vezes o neossoma tem carácter pegmatóide e existem estruturas pegmatíticas secantes à foliação e ao bandado migmatítico (Figura 3c). Porém algumas das estruturas pegmatíticas são posteriores ao Granito de Lavadores, porque cortam o contacto entre este e o maciço metamórfico envolvente.

Existem zonas lenticulares de espessura métrica de carácter diatexítico mesocrata, de granularidade grosseira e porfiróide, com encraves arredondados de paleossoma e algumas bandas de material melanocrata constituindo estruturas "schlieren" (Figura 3d). idênticas às descritas por Brown (2001). 


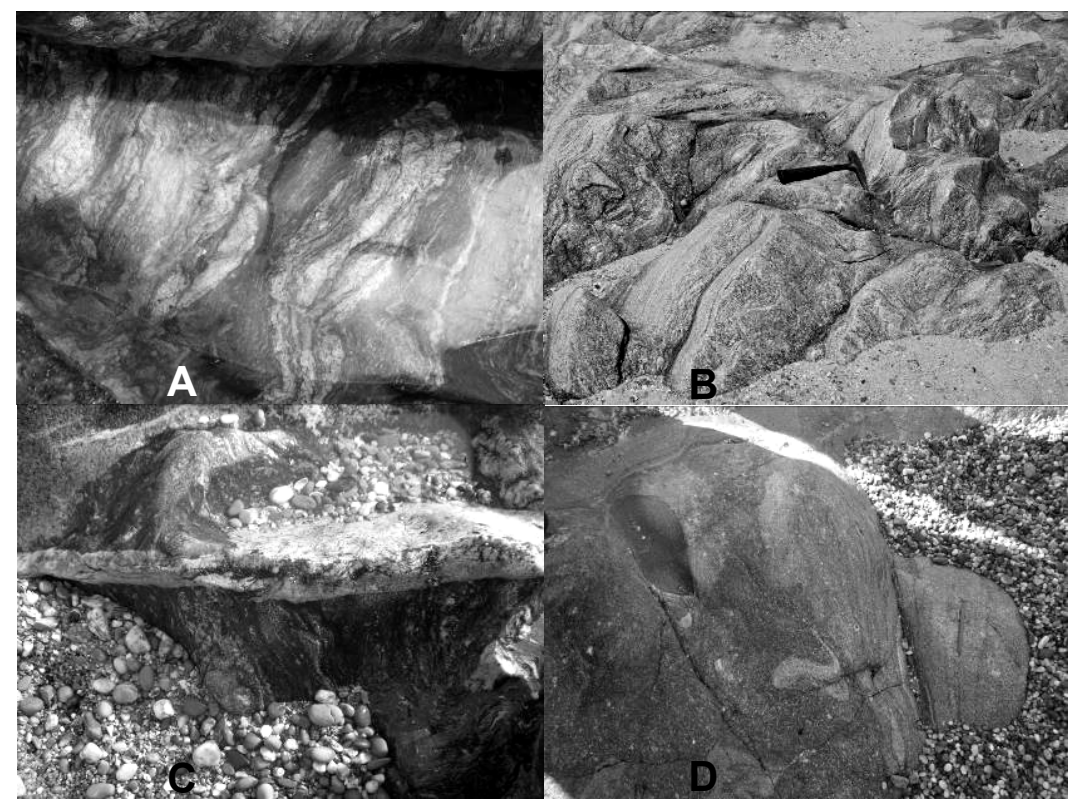

Figura 3. Aspectos litológicos dos matexitos (A, B e C) e dos diatexitos associados (D) (Praia da Madalena Sul).

\section{Petrografia}

O estudo petrográfico efectuado envolveu apenas as litologias diatexíticas leucocratas e mesocratas com biotite mais ou menos dispersa sem foliação ou definindo uma foliação incipiente e nos encraves restíticos metapelíticos. Os diatexitos apresentam bandado gnáissico marcado por diferenciação composicional. Apresentam uma mineralogia composta por: quartzo+ plagioclase + feldspato $\mathrm{K}+$ biotite $+/$ - cordierite $+/$ - granada $+/$ - andaluzite + magnetite+ hercinite. Nas estruturas "schlieren" e em encraves restíticos a mineralogia é composta por: biotite + silimanite + quartzo $+/-$ moscovite + magnetite + hercinite. A textura dos diatexitos é granular sem orientação preferencial embora a forma alongada dos nódulos restíticos e a sua distribuição marque uma orientação, mais ou menos evidente macroscopicamente.

A hercinite ocorre em aglomerados de pequenos cristais translúcidos de cor verde muito escura a negra, sempre em associação com silimanite fibrolítica e com magnetite (Figura 4). Apresenta uma composição rica en $\mathrm{Zn}$ e em $\mathrm{Mg}$ (cerca de 12\% de $\mathrm{ZnO}$ e de $\mathrm{MgO}$ ) (Ribeiro et al., 2010). 


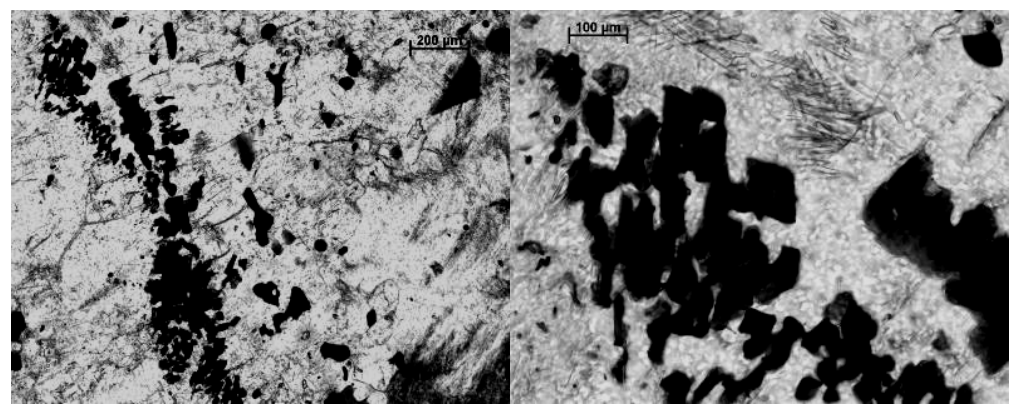

Figura 4. Aspectos textural da espinela hercínitica rica em $\mathrm{Zn}$, em associação com silimanite e magnetite.

\section{Considerações finais}

As litologias metatexíticas e diatexíticas aflorantes nas Praias do litoral de Vila Nova de Gaia apresentam deformação de carácter cisalhante, afectando paleossomas, leucossomas e mesossomas resultantes de um processo de migmatização por segregação e/ou por injecção, sin-cinemático relativamente à fase de deformação cisalhante. $\mathrm{O}$ carácter sin-cinemático da migmatização é interpretado com base nas relações geométricas e nas características litológicas das diversas fácies descritas, envolvendo fácies metapelíticas (micaxistos e quartzo-micaxistos), metatexitos com estrutura estromática, diatexitos leucocratas e diatexitos mesocratas. A ocorrência de hercinite rica em Zn, quer nos metassedimentos e nas estruturas "schlieren" quer nos núcleos restíticos dos diatexitos mesocratas, e o facto de a biotite não se observar em contacto com a espinela, ocorrendo esta em associação com a magnetite, a fibrolite e o quartzo, permite a interpretação de que a biotite foi consumida numa reacção de desidratação, geradora de hercinite, óxidos de Fe-Ti associados (série magnetite-ulvospinela) e "melt" (Ribeiro et al., 2010), tal como referido por Nex et al. (2001). A abundância de magnetite nos metapelitos, já evidenciada pelos elevados valores de Susceptibilidade Magnética e curvas de Magnetização Isotérmica Remanescente (Sant'Ovaia et al., 2009), e sua associação paragenética com espinela rica en $\mathrm{Zn}$, favorece a correlação destas rochas metapelíticas com litologias pertencentes ao Complexo Xisto-Grauváquico (CXG), que ocorrem um pouco a oriente desta faixa costeira, e que apresentam paragéneses ricas em estaurolite (Ribeiro et al., 2008).

É de salientar a referência à ocorrência de espinela hercínítica em anfibolitos da região de Torredeita (Viseu) (Neves \& Godinho, 1992) e o facto de Valle Aguado et al. (2010) descreverem na região NE de Viseu a existência de migmatitos diatexíticos e metatexíticos associados a 
metassedimentos com estaurolite relíquia. Estas duas referências relacionam-se ambas com o eixo de antiforma Porto-Viseu.

$\mathrm{O}$ maciço metamórfico descrito deverá corresponder ao bordo cisalhado da ZCI, ou poderá corresponder à cintura metamórfica PortoViseu (Valle Aguado \& Azevedo, 2006).

Não é de excluir que as condições de fusão fossem também facilitadas por advecção de fluidos metamórficos e/ou magmáticos, registados na ZCPT, numa fase sin-cinemática, prévia à instalação do maciço granítico de Lavadores. $\mathrm{O}$ facto de os diatexitos serem predominantes no sector mais a norte poderá ser indicador de estarem associados a uma zona com maior taxa de fusão. Contudo de acordo com Sawyer (2008) quando se verifica simultaneidade de fusão e de deformação, o movimento do "melt" é significativo, conduzindo a elevadas fluxos e concentrações em zonas de maior deformação, sem que seja significativo de maior taxa de fusão.

\section{Agradecimentos}

Este trabalhos insere-se nas actividades do Centro de Geologia da UP (CGUP), com o suporte financeiro da FCT, POCI 2010.

\section{Bibliografia}

Brown, M. (2001) - Orogeny, migmatites and leucogranites: A review. Proc. Indian Acad. Sci. (Earth Planet. Sci.); 110, 4, 313-336.

Carta Geológica de Portugal, escala 1:200 000, Folha 1. Serviços Geológicos de Portugal, 1992.

Chaminé, H.I. (2000) - Estratigrafia e estrutura da faixa metamórfica de Espinho - Albergaria-aVelha (Zona de Ossa Morena): inplicações geodinâmicas. Universidade do Porto (Tese de doutoramento); 497p.

Martins, H.C.B., Almeida, A., Noronha, F., Leterrier, J. (2001) - Novos dados geocronológicos de granitos da região do Porto e granito de Lavadores. Actas do VI Congresso de Geoquímica dos Países de Língua Portuguesa e XII Semana de Geoquímica, Univ. Algarve, Faro, 146148.

Neves, LF., Godinho, M.M. (1992) - Geologia da região de Torredeita (Viseu, Portugal Central) com especial ênfase para os granitóides. Memorias e Notícias, Publ. Mus. Lab. Geol. Univ Coimbra; 113: 1-28.

Nex, P.A.M., Oliver, G.J.H., Kimmaird, J.A. (2001) - Spinel-bearing assemblages and P-T-t evolution of the Central Zone of the Damara Orogen, Namibia. Journal of African Earth Sciences; 32, 3, 471-469

Oliveira, M., Noronha, F., Lima., A (2010) - Cartografia Geológica è escala 1/10.000da região SW da Folha Geológica 9C - Porto. Revista Electrónica de Ciências da Terra, Geosciences On-line Journal, e -Terra, http://e-terra.geopor.pt. ISSN 1645-0388; 22 (16).

Ribeiro, A., Pereira, E., Severo, L.G. (1980) - Análise da deformação na zona de cisalhamento PortoTomar, na transversal de Oliveira de Azeméis. Comun. Serv. Geol. Portg., Lisboa; 66, 3-9.

Ribeiro, M. A., Sant'Ovaia, H., Dória, A. (2010) - Ocorrência de hercinite em gnaisses e em metassedimentos da Praia de Lavadores (norte de Portugal). In: Flores, D \& Marques, M. 
(eds). X Congresso de Geoquímica dos Países de Língua Portuguesa. XVI Semana de Geoquímica. Memórias; 14, Resumos p.84; CD p. 183-190.

Ribeiro, M.A., Dória, A., Sant'Ovaia, H. (2008) - Relações entre deformação, magmatismo e metamorfismo na região oriental do maciço do Porto. In. Sant'Ovaia, H., Dória, A. \& Ribeiro, M.A .(eds), "GGET'08 - 8 Conferência Anual, 24-25 de Julho 2008" - Resumos alargados, Memórias n ${ }^{\circ} 13$, Univ. Porto, Faculdade de Ciências, Dep ${ }^{\circ}$ Geologia, 39-43.

Ribeiro, M.A., Sant'Ovaia, H., Dória, A. (2010) - Zn-rich hercynite-magnetite assemblage in gneiss and metasedimentary rocks from Lavadores (Northern Portugal). Geoch. Cosmoch. Acta. Goldschmidt Abstracts 2010; 74, (12, S1), A868.

Sant'Ovaia, H., Ribeiro, M.A., Cardoso, I. (2008) - Caracterização estrutural e metamórfica do sector Lavadores - Pedras Amarelas: Estudos de ASM. In. Sant'Ovaia, H., Dória, A. \& Ribeiro, M.A.(eds), "GGET'08 - 8 Conferência Anual, 24-25 de Julho 2008" - Resumos alargados; Univ. Porto, Faculdade de Ciências, Memórias; 13, Dep ${ }^{\circ}$ Geologia, 81-36.

Sant'Ovaia, H., Ribeiro, M.A., Gomes, C. (2009) - Magnetite-bearing mineral assemblages in igneous and metamorphic facies (N Portugal). Geoch. Cosmoch. Acta. Special supplement; 73 (13, S1): A1115.

Sawyer, E.W. (2008) - Atlas of Migmatites. The Canadian Mineralogist, Special Publications, 9, NRC Reseach Canal, Ontário, Canadá, 331p.

Stoddart, E.D. (1979) - Zinc-rich hercynite in high-grade metamorphic rocks: a product of the dehydration of staurolite. American Mineralogist; 64, 736-741.

Valle Aguado, B., Azevedo, M.R. (2006) - Trajectórias PTt na cintura metamórfica de Porto-Viseu: implicações no magmatismo granítico. VII Congresso Nacional de Geologia, Estremoz 2006. Livro de Resumos; III, 1215-1218.

Valle Aguado, B., Azevedo, M.R., Santos, J.F., Nolan, J. (2010) - O Complexo Migmatítico de Mundão (Viseu, norte de Portugal). Revista Electrónica de Ciências da Terra, Geosciences On-line Journal, e -Terra, http://e-terra.geopor.pt. ISSN 1645-0388; 16 (9). 